\title{
COVID-19 outbreak: The heart in the center?
}

\section{Christina Chrysohoou, Evangelos Oikonomou, Aggelos Papanikolaou, Panagiotis Xydis, Costas Tsioufis}

\author{
1st Cardiology Clinic, 'Hippokration' General Hospital, National and Kapodistrian University of Athens, \\ School of Medicine, Athens, Greece
}

\begin{abstract}
SARS-COV2 INFECTION has caused epidemic with an increased death toll that have surpassed the combined death tolls of previous acute respiratory syndromes. Due to the incremental role between COVID-19 infection and ACE2 activity, there are significant implication for cardiovascular complications, due to many reasons, like preexistence of cardiovascular disease; direct and indirect cardiovascular complications; adverse effects from therapies for COVID-19 under investigation. In this review epidemiological data; pathophysiological mechanisms; the implication of cardiovascular system and current therapeutic approach, are presented, according to recent published medical literature. Due to the incremental role between COVID-19 infection and ACE2 activity, there are significant implication for cardiovascular complications; while as renin-angiotensin system play a central role in the disease pathogenesis, there has been a large discussion how to handle medications related to this neurohormonal system. As subjects with increased reactivity of ACE-Angl-Angll axis show vulnerability in more symptomatic course of COVID-19 infection, all scientific societies underly that abrupt discontinuation of medication targeting on renin-angiotensin system in high-risk patients, including those who have arterial hypertension and heart failure, may result in clinical instability and adverse health outcomes.Anothre serious issue that has emerged for medical society is that the response to COVID-19 and the significant attention that is given for this medical condition, may compromise the rapid triage of nonCOVID-19 patients with other cardiovascular conditions.
\end{abstract}

KEY WORDS: COVID-19, cardiovascular disease

\section{INTRODUCTION}

COVID-19 epidemic, caused by coronavirus SARSCOV-2, has shown an increased death toll that has surpassed the combined death toll of previous Severe Acute

\section{Corresponding author:}

Christina Chrysohoou, MD, PhD, FESC

Vasilissis Sofias 114, PO 11528

Hippokration Hospital, Athens Greece

Tel: +30 2132088099 , Fax: +302132088676

e-mail: chrysohoou@usa.net
Respiratory Syndrome (SARS) epidemics ${ }^{1,2}$. Due to the internationally rapid spread of the virus, COVID-19 has been declared as a pandemic by World Heart Organization (WHO)on $11^{\text {th }}$ of March $2020^{3}$. COVID-19 was first presented as an acute respiratory disease with variable severity of symptoms, but currently observed disease patterns indicate that there are implications on cardiovascular system, even in patients without any known history of Cardiovas-

Submission: 28.09.2020, Acceptance: 05.11.2020 
cular Disease (CVD) that attribute to adverse outcome. In this brief review, epidemiological data; pathophysiological mechanisms; the implication of cardiovascular system and current therapeutic approach, are presented, according to recent published medical literature.

\section{Epidemiological data of COVID19 infection}

SARS-CoV2, as other members of the Corona-viridae family, is an enveloped virus with non-segmented single stranded, positive-sense RNA genome ${ }^{2-4}$. Some SARSrelated coronaviruses have been discovered in bats, as its genome is $96.2 \%$ identical to a bat coronavirus ${ }^{5}$. Since initial identification, the disease has spread to over 100 countries across the world. The up to now epidemiological data,according to $26^{\text {th }}$ of March 2020,present in 199 countries/areas with territory cases, 465,915 confirmed cases with 21,031 deaths ${ }^{3}$.The case fatality rate (CFR), -number of deaths/numbers of those diagnosed-differs significantly around the world. The original reports from China suggested a CFR of $2.3 \%$ with subsequent reports estimating the symptomatic case fatality risk (the probability of dying after developing symptoms) at 1.4\%, which contrasts with influenza (0.1\%), Middle East Respiratory Syndrome (MERS) (34\%), and SARS (10\%)(6). Furthermore, a variability in reported case fatality rates has occurred, due to several reasons, as: 1 ) the disease may be asymptomatic or mildly symptomatic in a large proportion of patients, 2) inadequate testing capabilities in most geographic areas, leading to frequent underdiagnosis, especially in patients with less serious illness, and 3) complications and death often ensue much later than contagion (typically between 2 and 3 weeks after infection $)^{7-8}$. Thus, as screening rate of the population differs among countries, any attempt for comparison in incidence and mortality rates between different regions can lead to untrusted assumptions, that can also have social implications.

SARS-CoV-2 is spread predominantly via respiratory droplets, but also can be aerosolized or detected in the stool; while transmission may occur from both symptomatic and asymptomatic patients, with median incubation time of 4-5 days with $97.5 \%$ of cases experiencing symptoms within 11.5 days of exposure. Most common symptoms are fever (88\%) and dry cough (67.7\%), which are shared with many other minor viral syndromes. Among those patients with more significant symptoms, $14 \%$ experience severe symptoms and 5\% critical respiratory failure, septic shock, and/or multiple organ dysfunction or failure ${ }^{9}$. The CFRis different among patients with co-morbidities, like arterial hypertension, cancer, diabetes mellitus, congestive heart failure and atherosclerosis.

\section{Pathogenesis of COVID19 infection}

The up to now knowledge indicate that post SARSCoV-2 infection, the invasion in human body is caused by binding of the viral surface spike protein to the human angiotensin-converting enzyme 2 (ACE2) receptor following activation of the spike protein by transmembrane protease serine 2 (TMPRSS2) $^{10}$. It is known that ACE2 is expressed in the lung, mainly at type II alveolar cells, as well as in the myocardium, kidney, liver, intestinal epithelium, and vascular endothelium, thus severe form of infection may lead to multi-organ insufficiency or failure ${ }^{11}$. Angiotensin converting enzyme 2 (ACE2) has gathered much attention as the cellular receptor for Severe Acute Respiratory Syndrome Coronavirus-2 (SARS-CoV-2), caused by COVID-19 ${ }^{12}$. ACE2 is a type I transmembrane protein that functions as a mono-carboxypeptidase with a catalytically active ectodomain exposed to the circulation that hydrolyzes various peptides, including angiotensin II (Ang II) and angiotensin I (Ang I) generating angiotensin 1-7 (Ang 1-7) and angiotensin 1-9, respectively. A soluble form of ACE2 can be released from the membrane through proteolytic cleavage mediated by ADAM17 resulting in loss of ACE2 protection against tissue renin-angiotensin system (RAS) and increased plasma ACE2 activity, a known marker of adverse prognosis in patients with CV disease.For the last 20 years angiotensinconvertingenzyme 1 (ACE) has been recognized for promoting formation of Ang II, which triggers vasoconstriction, inflammation, cell proliferation, hypertrophy, fibrosis and tissue remodeling. ACE2 has the robust effect to catalyze Ang II to the cardioprotective Ang 1-7, which acts through Mas receptors to counterbalance the detrimental effects of Ang II signaling. It seems that ACE2 protects against RAS-induced injuries through two processes, by (a) degrading Ang I and Ang II to limit substrate availability in the adverse ACE/Ang II/AT1 receptor axis, and (b) generating Ang 1-7 to increase substrate availability in the protective ACE2/Ang 1-7/Mas receptor axis ${ }^{10}$.After the initial engagement of SARS-CoV-2 spike protein, there is subsequent down-regulation of ACE2 abundance in cell surface. Down-regulation of ACE2 activity in the lungs facilitates the initial neutrophil infiltration in response to bacterial endotoxin and may result in unopposed angiotensin II accumulation and local RAAS activation. Dysregulated ACE2 may theoretically also attenuate cardio-protection in the context of myocardial involvement and abnormal pulmonary hemodynamics in COVID-19 ${ }^{13}$. Thus, subjects with increased reactivity of ACE-Angl-Angll axis show vulnerability in more symptomatic course of COVID-19 infection. Other potential explanations include advance age, a functionally impaired immune system and possible genetic predisposition. Data from the National 
Health Commission (NHC) of China demonstrated that $35 \%$ of patients diagnosed with COVID-19 had arterial hypertension and $17 \%$ coronary heart disease; while, a recent meta-analysis of eight studies from China including 46,248 infected patients revealed as the most prevalent comorbidities for more severe clinical course the existence of arterial hypertension (17 $\pm 7 \%$, 95\% Cl 14-22\%) and diabetes mellitus ( $8 \pm 6 \%, 95 \% \mathrm{Cl} 6-11 \%)$, followed by cardiovascular disease $(5 \pm 4 \%, 95 \% \mathrm{Cl} 4-7 \%)^{9,14}$. In addition, it could be hypothesis that when the virus uses ACE2 there is a negative feedback to ACE-1 activity, leading to increased release of bradykinin, which along with substance $P$ accumulate in the upper and lower respiratory tracts stimulating prostaglandins which also have effect on the lungs and also increase the cough reflex. This may be the initial mechanism of COVID-19, by further down regulating ACE1 activity and increasing substrate $P$; while in parallel bradykinin is increased leading to the crosstalk of kallikrein-bradykinin which also has impact on hemostatic system. Genetic polymorphisms may also play a role, as the degradation of bradykinin in circulation is much faster than that of ACE DD genotypes. These genotype prophylactic peptides appear to contribute to reducing respiratory concentrations of substance $P$ and bradykinin. When the virus enters the cell via ACE2, causes exaggeration of inflammation. In contrast to bradykinin receptor 2 (B2), the B1 receptor on endothelial cells is upregulated by proinflammatory cytokines. As, there is lack of ACE2 to inactivate the ligands of $B 1$, the lung environment is prone for local vascular leakage leading to angioedema. This can be featured early explaining the drowning feeling, along with the typical CT scans (Figure 1).

\section{Cardiovascular effects}

Due to the incremental role between COVID-19 infection and ACE2 activity, there are significant implication for cardiovascular complications. First, those patients with COVID-19 and preexisting CVD have an increasedrisk of severe disease and death (Table 1). Second, infection has been associated with multiple direct and indirectcardiovascular complications including acute myocardial injury, myocarditis, arrhythmias and venousthromboembolism. Third, therapies under investigation for COVID-19 may have cardiovascular sideeffects. Additionally, the response to COVID-19 and the significant attention that is given for this medical condition, may compromise the rapid triage of non-COVID-19 patients with other cardiovascular conditions $^{3}$.

Myocardial injury, in the form of acute myocarditis, usually defined by an increase in serum troponin levels can be found in patients with COVID-19 infection. In a meta-analysis of 4 studies including a total of 341 patients, standardized mean difference of cardiac troponin I levels were significantly higher in those with severe COVID-19 related illness compared to those with non-severe disease (25.6, 95\% Cl 6.8-44.5) $)^{15-16}$. Furthermore, acute cardiac injury,defined with cardiacbiomarkers elevations to $>$ 99th percentile of the upper reference limit, electrocardiographic andechocardiographic abnormalities, is highly prevalent in patients with COVID-19 and is associated withmore severe disease and worse prognosis. It has been estimated that such injury occurs in $7-17 \%$ of hospitalized patients andit is significantly morecommon in patients admitted to the critical care units and among those who died $(59 \% \text { vs. } 1 \%, \mathrm{p}<0.0001)^{4-5}$. However, troponin levels can be exacerbated in patients with renal insufficiency dueto delayed excretion, which is common in patients with advanced disease. Cardiac Magnetic resonance imaging may be useful in differentiating ischemic form non-ischemic origin of troponin elevation in those patients. Fulminant myocarditis may present a rare complication of COVID-19 infection, while myocardial infarction with nonobstructive coronary arteries(MINOCA) cases have also been described ${ }^{17}$. Patients with history of cardiovascular disease seems to be more susceptible to heart injury, as nearly 30 and $60 \%$ of critical ill patients with myocardial

TABLE 1. Relative frequency and Outcome according to cardiovascular risk factors (those data are extrapolated from mainly small studies $8,14,15,17,36-38$

\begin{tabular}{lccccccc}
\hline & $\begin{array}{c}\text { Relative } \\
\text { frequency }\end{array}$ & $\begin{array}{c}\text { Outcome } \\
\text { ICU }\end{array}$ & $\begin{array}{c}\text { Outcome } \\
\text { Non-ICU }\end{array}$ & $\begin{array}{c}\text { Outcome } \\
\text { severe }\end{array}$ & $\begin{array}{c}\text { Outcome } \\
\text { non-severe }\end{array}$ & $\begin{array}{c}\text { Outcome } \\
\text { Death }\end{array}$ & $\begin{array}{c}\text { Outcome } \\
\text { Alive }\end{array}$ \\
\hline Cardiovascular disease & $4.0-14.6 \%$ & $5.8 \%$ & $1.8 \%$ & $16.2 \%$ & $5.7 \%$ & $25.0 \%$ & $10.8 \%$ \\
\hline Arterial Hypertension & $6.5-34.7 \%$ & $15.4-58.3 \%$ & $14.3-21.6 \%$ & $23.7 \%$ & $13.4 \%$ & $48.1 \%$ & $23.4 \%$ \\
Diabetes Mellitus & $7.3-19.5 \%$ & $22 \%$ & $5.9 \%$ & $16.2 \%$ & $5.7 \%$ & $31.0 \%$ & $13.0 \%$ \\
\hline Smoking & $5.8-40 \%$ & $0 \%$ & $3.0 \%$ & $22.0 \%$ & $14.0 \%$ & $9.3 \%$ & $4.4 \%$ \\
Cerebrovascular disease & $1.4-8.0 \%$ & 16.7 & $1.0 \%$ & $2.3 \%$ & $1.2 \%$ & $10.3 \%$ & $6.1 \%$ \\
\hline
\end{tabular}

ICU: Intensive Care Unit 


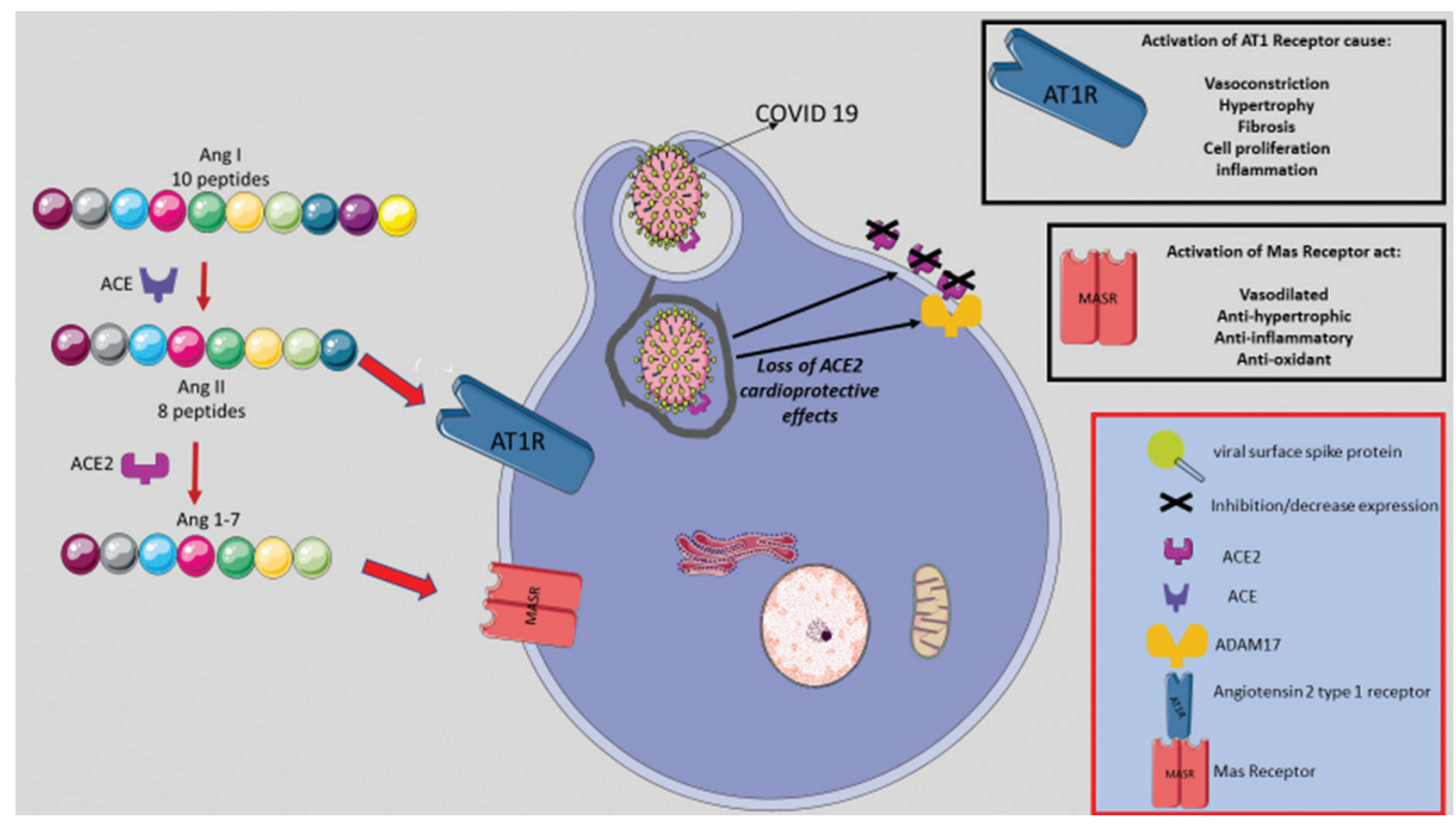

FIGURE 1. ACE2 balances RAS expression. Increased ACE2 increase the protective axis of ACE2/Ang 1-7/Mas receptor; while loss of it causes overexpression of ACE/Ang II/AT1 receptor axis. SARS-CoV-2 interacts with cell surface ACE2 and results in decrease surface ACE2 expression. This cause also upregulation to ADAM17 activity, which cleaves ACE2 from the cell membrane, perpetuating the loss of ACE2 from tissue RAS and accumulation of angiotensin II, which through AT1 receptors also upregulates ADAM17, resulting in further cleavage of cell surface ACE2.

ACE: Angiotensin converting enzyme; RAS: Renin angiotensin system; AT1: Angiotensin II type 1; Ang: Angiotensin; SARS-CoV-2: Severe Acute Respiratory Syndrome-Coronavirus 2

injury had personal history of coronary heart disease and arterial hypertension, respectively ${ }^{18,19}$. In a recent study in human heart tissues, ACE2 was highly expressed in pericytes of adult human hearts, which indicated an intrinsic susceptibility of heart to SARS-CoV-2 infection. Patients with basic heart failure disease exhibited increased expression of ACE2, and this may be related to their adverse outcome ${ }^{20}$.

Nonspecific heart palpitations have been also reported in affected individuals, up to a prevalence of $44 \%$ in critical ill patients. This can be mainly attributed to metabolic imbalance, hypoxia, neurohormonal or inflammatory stress; however new onset of malignant tachyarrhythmias in the setting of troponin elevation should raise suspicion for underlying myocarditis ${ }^{16,21}$. Heart failure has also been observed in about $23 \%$ of patients with COVID-19 infection and has been related with poor survival ${ }^{2}$. It is unclear if heart failure is due to decompensation of pre-existing left ventricular dysfunction or new cardiomyopathy. Thus, patients taking chronic treatment for heart failure or arterial hypertension with the use of ACE-inhibitors or Angiotensin receptors blockers are encouraged to con- tinue. Additionally, Nt-proBNP peptide may be useful for the differentiation of cardiogenic from non-cardiogenic pulmonary edema22. Extracorporeal membranous oxygenation (ECMO) has been used in cases of circulation collapse with concomitant cardiogenic component, but with poor results ${ }^{23}$. There is also an increased risk for venous thromboembolic disease, although spare data exist in literature. In amulticenter retrospective cohort study from China, elevated D-dimer levels ( $>1 \mathrm{~g} / \mathrm{L}$ ) were stronglyassociated with in-hospital death, even after multivariable adjustment (OR 18.4 95\% Cl 2.6-128.6,p=0.003) (3); while $71 \%$ of non-survivors seems to meet clinical criteria for disseminated intravascular coagulation (DIC) during the course of their disease ${ }^{24}$. Several factors may attribute to increased thromboembolic risk, as prolonged immobilization, vascular inflammation, and endothelialdysfunction; although the optimal thrombo-prophylactic regimen for patients hospitalized with COVID-19 related illness is not known.In any case, in any deterioration of clinical status as evidenced by hypoxia or hemodynamic instability, thromboembolic disease should beconsidered.

Long-term follow up data concerning the survivors 
of respiratory virus epidemics are scarce in literature, although in one study the clinical effects of pneumonia have been linked with increased cardiovascular risk in long-term follow up. ${ }^{25}$. It seems that in survivors of hospitalization for community-acquired pneumonia long after recovery, elevated systemic inflammatory and procoagulant activity can persist, but in the case of COVID-19 more data are required.

\section{Potential therapeutic implications}

The best treatment up to now, is prevention (Table 2). Vaccines and monoclonal antibodies against SARS-COV-2 are under development. Chloroquine (anti-malarial drug) and hydroxychloroquine, which is used in rheumatoid arthritis or systemic lupus erythematosus treatment, can block SARS-CoV-2 cell entry in vitro. Additionally, the serine protease inhibitor camostat mesylate, which is approved in Japan for chronic pancreatitis and postoperative reflux esophagitis among other indications, has been shown to block TMPRSS2 activity and inhibit SARS-CoV entry into cells. Ribavirin and lopinavir/ritonavir, that have been used for years as components of treatment for hepatitis $\mathrm{C}$ and human immunodeficiency virus (HIV), are under investigation in clinical trials for COVID-1926,27 (Table 3). Recombinant human ACE2 in being studied in clinical trials. Previous studies with intravenous infusion of recombinant human ACE2 (rhACE2) in patients with pulmonary arterial hypertension and acute lung injury had reported immediate decreases in plasma Ang II/Ang 1-7 ratios reflecting ACE2 functions and its therapeutic effects. Thus, systemic delivery of rhACE2 $(0.4 \mathrm{mg} / \mathrm{kg}$ i.v. twice a day for seven days) will hopefully sequester viral SARS-CoV-2 particles in the circulation preventing their interaction and subsequent

TABLE 2. Considerations for Health care providers and population as presented by WHO Director-General's opening remarks at the media briefing onCOVID-193

\begin{tabular}{l}
\hline - E-visits, tele-monitoring for patients, when it is feasible \\
- Adhere to guidelines for optimal use of prophylactic medical \\
material \\
- Self-reporting of all suspicious (cough, fever, flu-like, symptoms) \\
and halting role \\
- Limit elective procedure (echocardiography catheterization) to \\
only urgent/emergent \\
- Improve testing availability for population \\
- Improve population education \\
- Initiate or improve e-health programs for patients \\
- Limit in person visit and in person consultation
\end{tabular}

WHO: World Health Organization internalization through endogenous ACE2 receptors while also activating the systemic protective axis of the RAS ${ }^{28}$.

There has been a large discussion about handling of antihypertension therapy of patients, as arterial hypertension has been reported to be more common in seriously hospitalized patients with COVID-19. Although there were some concerns about the role of renin-angiotensin-aldosterone system (RAAS) inhibition, if it exaggerates ACE-2 activity; there is lack of scientific support as in population-based studies in China only $20-30 \%$ of hypertensive patients under treatment take RAAS inhibition ${ }^{29}$. A recent hypothesis suggested that angiotensin receptor 1 inhibitors might be beneficial for patients infected by COVID-19. It seems that SARS-CoV-2 infected patients that are chronically medicating with angiotensin II type 1 receptor (AT1R) blockers, although having higher ACE2 expression, may be protected from lung injury. This may be due to two complementary mechanisms, by blocking the excessive angiotensin-mediated AT1R activation caused by the viral infection, and by upregulating ACE2, thereby reducing angiotensin production by $A C E$ and increasing the production of the vasodilator angiotensin $1-7^{30}$. In a previous study, intravenous administration of ACE inhibitors in patients with coronary artery disease did not have any impact on angiotensin-(1-7) production; which arises the thought if ACE inhibitors have any direct effects on ACE2-directed angiotensin II metabolism ${ }^{31}$. Furthermore, in cross-sectional studies, patients with heart failure, atrial fibrillation, aortic stenosis, and coronary artery disease, who were under RAAS inhibition treatment, did not show higher plasma ACE2 activity, compared to untreated patients ${ }^{32}$. In the case of COVID-19 infection, those patients with adverse outcome had elevated levels of plasma angiotensin II, which were in turn correlated with total viral load and degree of lung injury; while in autopsies the presence of viral RNA in cardiac species was associated with reduced ACE2 protein expression ${ }^{13}$. It seems that administration of recombinant ACE2 normalizes angiotensin II levels in human explanted hearts with dilated cardiomyopathy. Thus, clinical trials are tested whether the provision of recombinant ACE2 protein may be beneficial in restoring balance to the RAAS network and potentially preventing organ injury ${ }^{13}$. Additionally, RAAS inhibition may suppress fibroblast growth factor 23(FGF23)/Klotho/phosphate axis, as high levels of FGF-23 or FGF-23 resistance, due to klotho deficiency, are associated with endothelial dysfunction and cardiovascular morbidity and mortality ${ }^{33}$.

As, more data are warranted to support this hypothesis, we must underly that abrupt withdrawal of RAAS inhibitors in high-risk patients, including those who have heart failure, may result in clinical instability and adverse health outcomes. 
TABLE 3. Antiviral Therapies with potential use for COVID 19 infections s,21 $^{2,1}$

\begin{tabular}{|c|c|c|c|c|}
\hline Antiviral therapy & Mechanisms & Drug Interactions & Adverse effects & Common use \\
\hline Ribavirin & $\begin{array}{l}\text { Unknown mechanism } \\
\text { of action }\end{array}$ & Warfarin & Monitor INR & $\begin{array}{l}\text { Syncytial virus infection, } \\
\text { hepatitis } C \text {, hemorrhagic fever }\end{array}$ \\
\hline Lopinavir/ Ritonavir & CYP3A4 inhibition & $\begin{array}{l}\text { Rivaroxaban should be } \\
\text { interrupted, apixaban } \\
\text { dose reduced to } 50 \% \text {. } \\
\text { Clopidogrel; Ticagrelor } \\
\text { should be interrupted. } \\
\text { Lower dose for Atorvastatin } \\
\text { and Rosuvastatin }\end{array}$ & $\begin{array}{l}\text { QTc prolongation, } \\
\text { combines with } \\
\text { amiodarone may cause } \\
\text { fatal arrhythmia; } \\
\text { Can be used in pregnancy }\end{array}$ & HIV \\
\hline Remdesevir & $\begin{array}{l}\text { Nucleotideanalog } \\
\text { inhibitor of } \\
\text { RNAdependent RNA } \\
\text { polymerases }\end{array}$ & Unknown & Unknown & Ebola virus \\
\hline Bevacizumab & Inhibition ofVEGF & Unknown & $\begin{array}{l}\text { Decrease vascular } \\
\text { permeability and } \\
\text { pulmonary edema;Direct } \\
\text { myocardial toxicity; } \\
\text { Severe hypertension; } \\
\text { Thromboembolic events }\end{array}$ & Cancer \\
\hline $\begin{array}{l}\text { Chloroquine/ } \\
\text { Hydroxychloroquine }\end{array}$ & $\begin{array}{l}\text { Alters endosomal } \mathrm{pH} \\
\text { required for virus/cell } \\
\text { fusion }\end{array}$ & Antiarrhythmics & $\begin{array}{l}\text { Monitor digoxin levels and } \\
\text { ECG; Myocarditis. } \\
\text { Avoid in pregnancy }\end{array}$ & Malaria, RA \\
\hline Eculizumab & $\begin{array}{l}\text { Inhibits complement } \\
\text { activation }\end{array}$ & Unknown & Edema; hypertension & \\
\hline Interferon & Immune activation & Unknown & $\begin{array}{l}\text { Myocardial toxicity, } \\
\text { hypotension, arrhythmia, } \\
\text { cardiomyopathy, } \\
\text { myocardial infarction }\end{array}$ & Rheumatic disease \\
\hline Pirfenidone & $\begin{array}{l}\text { Antifibrotic ability, } \\
\text { possible IL-1 } \beta \text { and IL-4 } \\
\text { inhibition to reduce } \\
\text { cytokine storm and } \\
\text { resultant pulmonary } \\
\text { fibrosis }\end{array}$ & Unknown & Unknown & Idiopathicpulmonaryfibrosis \\
\hline Methylprednisolone & $\begin{array}{l}\text { Alters gene expression to } \\
\text { reduce inflammation }\end{array}$ & Anticoagulants & $\begin{array}{l}\text { Monitor INR } \\
\text { Fluid retention; } \\
\text { Electrolyte disturbances; } \\
\text { Hypertension }\end{array}$ & $\begin{array}{l}\text { Inflammation; rheumatic } \\
\text { diseases }\end{array}$ \\
\hline Tocilizumab & Inhibits IL-6 receptor & Unknown & $\begin{array}{l}\text { Hypertension, increased } \\
\text { serum cholesterol }\end{array}$ & \\
\hline Azithromycin & $\begin{array}{l}\text { Binds to the } 50 \text { subunit } \\
\text { of the bacterial ribosome, } \\
\text { inhibiting translation of } \\
\text { mRNA, anti-inflammatory }\end{array}$ & With drugs prolong QTC & $\begin{array}{l}\text { QTc prolongation, } \\
\text { Can be used in pregnancy } \\
\text { cholestatic hepatitis or } \\
\text { delirium }\end{array}$ & Bacterial infection;Malaria \\
\hline Colchicine & $\begin{array}{l}\text { Antimitotic; Lack of } \\
\text { studies for COVID } 19\end{array}$ & Interacts CYP3A4 enzyme & $\begin{array}{l}\text { Fatal drug interactions } \\
\text { have occurred when } \\
\text { colchicine was taken } \\
\text { with other drugs that } \\
\text { inhibit P-glycoprotein and } \\
\text { CYP3A4, risk for toxicity } \\
\text { when liponavir, ritonavir, } \\
\text { statin are co-administered }\end{array}$ & Pericarditis, gout \\
\hline
\end{tabular}

INR: International normalized ratio; CYP: Cytochrome P450; HIV; Human Immunodeficiency virus; VEGF: Vascular endothelial growth factor; RA: Rheumatoid arthritis; IL: Interleukin 
Some discussions have raised if there is therapeutic role by the administration of colchicine. This well-known medication appears to inhibit multiple proinflammatory mechanisms, while enabling increased levels of antiinflammatory mediators. Apart from inhibiting mitosis, colchicine inhibits neutrophil motility and activity, leading to a net anti-inflammatory effect, which has efficacy for inhibiting or preventing gout inflammation, pericardial disease, the recurrences of atrial fibrillation post ablation therapy and in bare-metal coronary stent restenosis ${ }^{34,35}$. There are no clinical data, at this time to support its use in COVID 19 infections, although clinical trials are now being conducted.

\section{CONCLUSION}

Due to the incremental role between COVID-19 infection and ACE2 activity, there is significant implication for cardiovascular complications. Especially those patients with arterial hypertension, diabetes mellitus and coronary artery disease, face an increased risk for adverse events. Myocardial injury is present in more than a quarter of critical cases and presents even on presentation as acute myocardial injury or later as the illness severity intensifies. The continuation of clinically indicated ACEi and ARB treatment is recommended based on the available literature. Potential other treatment modalities are under investigation. Finally, the significant attention that has been given for COVID-19 infection should not compromise our medical attention for other cardiovascular conditions in our patients.

\section{REFERENCES}

1. Huang C, Wang Y, Li X, Ren L, Zhao J, Hu Y, et al. Clinical features of patients infected with 2019 novel coronavirus in Wuhan, China. Lancet. 2020 Feb;395(10223):497-506.

2. Driggin E, Madhavan MV, Bikdeli B, Chuich T, Laracy J, Bondi-Zoccai G, et al. Cardiovascular Considerations for Patients, Health Care Workers, and Health Systems During the Coronavirus Disease 2019 (COVID-19) Pandemic. J Am Coll Cardiol. 2020 May;75(18):2352-71.

3. WHO Director-General's opening remarks at the media briefing onCOVID-19: World Health Organization [Internet]. WHO; 2020 [cited YEAR MONTH DAY]. Available from: https://www.who.int/dg/speeches/detail/who-directorgeneral-s-opening-remarks-at-the-media-briefing-oncovid-19---30-march-2020.

4. Zhou P, Yang XL, Wang XG, Hu B, Zhang L, Zhang W, et al. A pneumonia outbreak associated with a new coronavirus of probable bat origin. Nature. 2020 Feb;579(7798):270-3.

5. Su S, Wong G, Shi W, Liu J, Lai ACK, Zhou J, et al. Epidemiology, Genetic Recombination, and Pathogenesis of Coronaviruses. Trends Microbiol. 2016 Jun;24(6):490-502.

6. Dong E, Du H, Gardner L. An interactive web-based dashboard to track COVID-19 in real time. Lancet Infect Dis. 2020 May;20(5):533-4.

7. Andersen KG, Rambaut A, Lipkin WI, Holmes EC, Garry RF. The proximal origin of SARS-CoV-2. Nature Medicine. 2020 Mar;26:450-2.

8. Wu Z, McGoogan JM. Characteristics of and Important Lessons From the Coronavirus Disease 2019 (COVID-19) Outbreak in China: Summary of a Report of 72314 Cases From the Chinese Center for Disease Control and Prevention. JAMA. 2020 Feb;323(13):1239-42.

9. Zheng YY, Ma YT, Zhang JY, Xie X. COVID-19 and the cardiovascular system. Nat Rev Cardiol. 2020 May;17(5):259-60.

10. Zhang H, Penninger JM, Li Y, Zhong N, Slutsky AS. Angiotensin-converting enzyme 2 (ACE2) as a SARS-CoV-2 receptor: molecular mechanisms and potential therapeutic target. Intensive Care Med. 2020 Apr;46(4):586-90.

11. Hoffmann M, Kleine-Weber H, Schroeder S, Kruger N, Herrler T, Erichsen S, et al. SARS-CoV-2 Cell Entry Depends on ACE 2 and TMPRSS2 and Is Blocked by a Clinically Proven Protease Inhibitor. Cell. 2020 April;181(2):271-80.

12. Clerkin KJ, Fried JA, Raikhelkar J, Sayer G, Griffin JM, Masoumi A, et al. Coronavirus Disease 2019 (COVID-19) and Cardiovascular Disease. Circulation. 2020 Mar;141(20):1648-55.

13. Vaduganathan M, Vardeny O, Michel T, McMurray JJV, Pfeffer MA, Solomon SD. Renin-Angiotensin-Aldosterone System Inhibitors in Patients with Covid-19. N Engl J Med. 2020 Apr;382(17):1653-9.

14. Yang J, Zheng Y, Gou X, Pu K, Chen Z, Guo Q, et al. Prevalence of comorbidities and its effects in patients infected with SARS-CoV-2: a systematic review and meta-analysis Int J Infect Dis. 2020 May;94:91-5.

15. Yang X, Yu Y, Xu J, Shu H, Xia J, Liu H, et al. Clinical course and outcomes of critically ill patients with SARS-CoV-2 pneumonia in Wuhan, China: a single-centered, retrospective, observational study. Lancet Respir Med. 2020 May;8(5):475-81.

16. Lippi G, Lavie CJ, Sanchis-Gomar F. Cardiac troponin I in patients with coronavirus disease 2019 (COVID-19): Evidence from a meta-analysis. Prog Cardiovasc Dis. 2020 May-Jun;63(3):390-1.

17. Wood S. TCT the Heat Beat: COVID-19 and the Heart: Insights from the Front Lines. [Internet] 2020 [cited YEAR MONTH DAY]. Available from: https://www.tctmd.com/ news/covid-19-and-heart-insights-front-lines.

18. Wang D, Hu B, Hu C, Zhu F, Liu X, Zhang J, et al. Clinical Characteristics of 138 Hospitalized Patients With 2019 Novel Coronavirus-Infected Pneumonia in Wuhan, China. JAMA. 2020 Mar;323(11):1061-9.

19. Shi S, Qin M, Shen B, Cai Y, Liu T, Yang F, et al. Association of cardiac injury with mortality in hospitalized patients with COVID-19 in Wuhan, China. JAMA Cardiol. 2020 Mar;5(7):802-10.

20. Chen L, Li X, Chen M, Feng Y, Xiong C. The ACE2 expression in human heart indicates new potential mechanism of heart injury among patients infected with SARS-CoV-2. Cardiovasc Res. 2020 May;116,(6):1097-100.

21. Xiong TY, Redwood S, Prendergast B, Chen M. Coronaviruses and the cardiovascular system: acute and long-term implications. Eur Heart J. 2020 May;41(19):1798-800.

22. Karmpaliotis D, Kirtane AJ, Ruisi CP, Polonsky T, Malhotra 
A, Talmor D, et al. Diagnostic and prognostic utility of brain natriuretic Peptide in subjects admitted to the ICU with hypoxic respiratory failure due to noncardiogenic and cardiogenic pulmonary edema. Chest. 2007 Apr;131(4):964-71.

23. MacLaren G, Fisher D, Brodie D. Preparing for the Most Critically III Patients With COVID-19: The Potential Role of Extracorporeal Membrane Oxygenation. JAMA. 2020 Apr;323(13):1245-6.

24. Tang N, Li D, Wang X, Sun Z. Abnormal coagulation parameters are associated with poor prognosis in patients with novel coronavirus pneumonia. J Thromb Haemost. 2020 Apr;18(4):844-7.

25. Corrales-Medina VF, Alvarez KN, Weissfeld LA, Angus DC, Chirinos JA, Chang CC, et al. Association between hospitalization for pneumonia and subsequent risk of cardiovascular disease. JAMA. 2015 Jan;313(3):264-74.

26. Kawase M, Shirato K, van der Hoek L, Taguchi F, Matsuyama S. Simultaneous treatment of human bronchial epithelial cells with serine and cysteine protease inhibitors prevents severe acute respiratory syndrome coronavirus entry. J Virol. 2012 Jun;86(12):6537-45.

27. Wang M, Cao R, Zhang L, Yang X, Liu J, Xu M, et al. Remdesivir and chloroquine effectively inhibit the recently emerged novel coronavirus (2019-nCoV) in vitro. Cell Res. 2020 Feb;30(3):269-71.

28. Wang K, Gheblawi M, Oudit GY. Angiotensin Converting Enzyme 2: A Double-Edged Sword. Circulation [Internet]. 2020 Mar. Available from: https://pubmed.ncbi.nlm.nih. gov/32213097/.

29. Wang Z, Chen Z, Zhang L, Wang X, Hao G, Zhang Z, et al. Status of Hypertension in China: Results From the China Hypertension Survey, 2012-2015. Circulation. 2018 May;137(22):2344-56.

30. Gurwitz D. Angiotensin receptor blockers as tentative SARS-CoV-2 therapeutics. Drug Dev Res [Internet]. 2020
Mar. Available from: https://www.ncbi.nlm.nih.gov/pmc/ articles/PMC7228359/

31. Walters TE, Kalman JM, Patel SK, Mearns M, Velkoska E, Burrell LM. Angiotensin converting enzyme 2 activity and human atrial fibrillation: increased plasma angiotensin converting enzyme 2 activity is associated with atrial fibrillation and more advanced left atrial structural remodelling. Europace. 2017 Aug;19(8):1280-7.

32. Ramchand J, Patel SK, Kearney LG, Matalanis G, Farouque O, Srivastava PM, et al. Plasma ACE2 activity predicts mortality in aortic stenosis and is associated with severe myocardial fibrosis. JACC Cardiovasc Imaging. 2020 Oct;13(3):655-64.

33. de Borst MH, Vervloet MG, ter Wee PM, Navis G. Cross talk between the renin-angiotensin-aldosterone system and vitamin D-FGF-23-klotho in chronic kidney disease. J Am Soc Nephrol. 2011 Sep;22(9):1603-9.

34. Deftereos S, Giannopoulos G, Papoutsidakis N, Panagopoulou V, Kossyvakis C, Raisakis K, et al. Colchicine and the heart: pushing the envelope. J Am Coll Cardiol. 2013 Nov;62(20):1817-25.

35. Lazaros G, Imazio M, Brucato A, Vlachopoulos C, Lazarou $E$, Vassilopoulos D, et al. The Role of Colchicine in Pericardial Syndromes. Curr Pharm Des. 2018 Jan;24(6):702-9.

36. Zhou F, Yu T, Du R, Fan G, Liu Y, Liu Z, et al. Clinical course and risk factors for mortality of adult inpatients with COVID-19 in Wuhan, China: a retrospective cohort study. Lancet. 2020 Mar;395(10229):1054-62.

37. Wu C, Chen X, Cai Y, Xia J, Zhou X, Xu S, et al. Risk Factors Associated With Acute Respiratory Distress Syndrome and Death in Patients With Coronavirus Disease 2019 Pneumonia in Wuhan, China. JAMA Intern Med. 2020 Mar;180(7):934-943.

38. Guan WJ, Ni ZY, Hu Y, Liang WH, Ou CQ, He JX, et al. Clinical Characteristics of Coronavirus Disease 2019 in China. N Engl J Med. 2020 Feb;382:1708-20. 